\title{
Reduction of functional cardiovascular reserve in the stages of chronic kidney disease
}

\author{
(iD) Juliana Schneider ${ }^{1,4}$ \\ Daula Caitano Fontela $a^{1,2,4}$ \\ (iD) Matias Nunes Frizzo ${ }^{1,3}$ \\ (1DLigia Beatriz Bento Franz ${ }^{1,3}$ \\ (iD) Olvânia Basso de Oliveira ${ }^{4}$ \\ (D) Eliane Roseli Winkelmann ${ }^{1,3}$
}

\begin{abstract}
1. Departamento de Ciências da Vida, Universidade Regional do Noroeste do Estado do Rio Grande do Sul, ljuí, RS, Brasil. 2. Programa de Pós-Graduação em Ciências Pneumológicas, Universidade Federal do Rio Grande do Sul, Porto Alegre, RS, Brasil. 3. Programa de Pós-Graduação em Atenção Integral à Saúde, Universidade Regional do Noroeste do Estado do Rio Grande do Sul, ljuí, RS, Brasil.

4. Hospital de Caridade de ljuí, ljuí, RS, Brasil. This work is associated with the Universidade Regional do Noroeste do Estado do Rio Grande do Sul.
\end{abstract}

http://dx.doi.org/10.1590/1806-9282.66.4.437

\section{SUMMARY}

OBJECTIVE: Patients with chronic kidney disease (CKD) present reduced oxygen consumption at peak exercise (VO, peak). No studies have evaluated objective measures of the cardiovascular reserve, besides $\mathrm{VO}_{2}$ peak and $\mathrm{VO}_{2}$ at the anaerobic threshold $\left(\mathrm{VO}_{2} \mathrm{AT}\right)$, and compared these measures among ckd patients at different stages of the disease.

METHODS: Fifty-eight patients [pre-dialysis group $(P D)=26$, hemodialysis group $(H D)=20$, and post-kidney transplant group $(K T)=12$ ] were included. The following measures of cardiovascular reserve were obtained: 1) peak heart rate (HR); 2) peak systolic blood pressure (SBP); 3) $\mathrm{VO}_{2}$ peak and \% predicted; 4) $\mathrm{VO}_{2} \mathrm{AT}$ and $\%$ of predicted $\mathrm{VO}_{2}$; 5) peak circulatory power; 6) ventilatory efficiency for the production of carbon dioxide (VE/VCO, slope); 7) oxygen uptake efficiency slope (OUES); and 8) recovery of gas exchange.

RESULTS: The $\mathrm{VO}_{2}$ peak and $\mathrm{VO}_{2}$ AT in the PD, HD, and $K T$ groups were reduced to $86 \%$ and $69 \%, 70 \%$ and $57 \%$, and $79 \%$ and $64 \%$ of the predicted value, respectively. Patients in the HD group had lower $\mathrm{VO}_{2}$ peak (17.5 $\pm 5.9 \mathrm{vs} .23 .2 \pm 8.2[p$-value $\left.=0.036]\right)$ and $\mathrm{VO}{ }_{2} A T$ (14.0 \pm 5.2 vs. $18.3 \pm 4.7$ [p-value $=0.039]$ ) compared to patients in the KT group. OUES was significantly lower in the HD group compared to the KT group (p-value=0.034). Age in the PD, HD, and KT groups and sedentary lifestyle in the KT group were predictors of $\mathrm{VO}_{2}$ peak.

CONCLUSIONS: CKD patients presented a reduction in cardiovascular reserve regardless of the stage of the disease. However, hemodialysis patients presented a greater reduction of cardiovascular reserve when compared to post-kidney transplant patients.

KEYWORDS: Renal insufficiency, chronic. Exercise test. Kidney transplantation. Renal dialysis.

\section{INTRODUCTION}

The cardiopulmonary exercise test (CPET) is considered a standard reference in the evaluation of cardiopulmonary and metabolic responses to aerobic exercise in patients with cardiovascular diseases'.
Patients with chronic kidney disease (CKD) are at high risk for cardiovascular disease ${ }^{2}$. Complex changes in the cardiovascular system of CKD patients result in structural and functional changes that may lead

DATE OF SUBMISSION: 08-Aug-2019

DATE OF ACCEPTANCE: 31-Aug-2019

CORRESPONDING AUTHOR: Eliane Roseli Winkelmann

Rua do Comércio, 2000, ljuí, RS, Brasil - 98700-000

Tel: +55 33322000

E-mail: elianew@unijui.edu.br 
to reduced tolerance to exercise and quality of life, increased morbidity, and finally, premature death ${ }^{3}$.

Exercise capacity depends on the health of the cardiovascular system in maintaining the transport of oxygen and carbon dioxide between the cellular and pulmonary systems ${ }^{4}$. A reduction in exercise capacity limits the range of physical activities a patient can perform. Several measures of the functional cardiovascular reserve, in addition to those traditionally used, can be obtained from a CPET and have been used to evaluate patients with heart failure ${ }^{5,6}$.

Several studies have already demonstrated a reduction in the functional cardiovascular reserve through a reduction of oxygen uptake at peak exercise $\left(\mathrm{VO}_{2}\right.$ peak $)$ in CKD patients ${ }^{7-10}$. However, we are not aware of any previous studies that evaluated objective measures of the cardiovascular reserve, besides $\mathrm{VO}_{2}$ peak and $\mathrm{VO}_{2}$ at the anaerobic threshold (AT), and compared these measurements among CKD patients at different stages of the disease. Therefore, the objective of this study was to evaluate measures of functional cardiovascular reserve in CKD patients at different stages of the disease [pre-dialysis (PD), hemodialysis (HD), and post-kidney transplant (KT)] and to determine the predictors of $\mathrm{VO}_{2}$ peak in these groups of patients. We hypothesized that although these patients have CKD in common, measurements of functional cardiovascular reserve would be significantly different in the different stages of CKD. The knowledge of these changes and differences may guide the treatment and implementation of preventive measures for other diseases, especially cardiovascular ones, which may occur due to renal disease.

\section{METHODS}

\section{Study design}

A secondary analysis was carried out using the dataset of research performed with patients who were submitted to pre-dialysis treatment, hemodialysis, or kidney transplant under follow-up at the Nephrology Unit of the Charity Hospital of Ijuí-RS. The pieces of research were cross-sectional studies conducted between 2012 and 2014. The researcher responsible for the dataset approved its use.

Patients were included in this study if they were at least 18 years old and had all data from the evaluation protocol in the databases, which included complete clinical evaluation, laboratory analysis, and cardiopulmonary testing.

\section{Study population}

A total of 241 patients were followed up at the Nephrology Unit of the Charity Hospital of Ijuí-RS and screened between 2012 and 2014. From this total, 72 patients were included in previous research, of which 58 had complete biochemical and exercise capacity data and, therefore, were analyzed in this study (Fig. 1).

\section{Data collection and variables}

Clinical and demographic data were recorded, including age, sex, CKD etiology, time of current treatment, weight, height, body mass index (BMI), and presence of cardiovascular risk factors [sedentary lifestyle, systemic arterial hypertension (SAH), diabetes mellitus (DM), alcoholism, and smoking]. The laboratory data of creatinine, urea, potassium, hemoglobin, and hematocrit were collected from recent hematological and biochemical tests whose values were recorded on the medical records of the patients who were registered in the databases.

The CPET or maximum incremental exercise test was performed on a treadmill (Imbrasport, Porto Alegre, Brasil), with the following ramp protocol: initial speed of $1 \mathrm{~km} \cdot \mathrm{h}^{-1}$ and final speed of $6 \mathrm{~km} \cdot \mathrm{h}^{-1}$; and initial inclination of $0 \%$ and final inclination of $10 \%$. Exhausted gases were analyzed every 20 seconds through a gas analyzer (total metabolic analysis system, TEEM 100, Aero Sport, Ann Arbor, Michigan). Blood pressure was measured every 3 minutes with a sphygmomanometer. Heart rate (HR) was determined using the R-R interval from 12 electrocardiogram leads. The CPET variables were calculated as described by Dall'Ago et al. ${ }^{11}$. In summary, the $\mathrm{VO}_{2}$ peak was defined as the highest value achieved during the test for 20 seconds, and peak circulatory power was calculated as the product of $\mathrm{VO}_{2}$ peak and peak systolic blood pressure (peak SBP). The recovery kinetics of oxygen uptake $\left(\mathrm{T}_{1 / 2} \mathrm{VO}_{2}\right)$ was evaluated as the time required for a $50 \%$ decrease from the $\mathrm{VO}_{2}$ peak and calculated using the least-squares model, according to Dall'Ago et al. ${ }^{11}$. The oxygen uptake efficiency slope (OUES) was calculated as the slope of the linear regression line between $\mathrm{VO}_{2}$ and the logarithm of ventilation $(\mathrm{VE})^{12}$. The evaluation of ventilatory efficiency was calculated using the linear regression model relating the VE and carbon dioxide production $\left(\mathrm{VCO}_{2}\right)$ during the exercise. For this, data from the entire cardiopulmonary test were used, from the beginning to the peak of the exercise. The slope values of the $\mathrm{VE} / \mathrm{VCO}_{2}$ ratio line were used for the analysis of ventilatory efficiency. 
The first ventilatory threshold (also known as the anaerobic threshold) was determined by reviewing the gas exchange curves and was the heart rate in which the ventilatory equivalent for oxygen increases systematically without an increase in the ventilatory equivalent for carbon dioxide'. The prediction equation of the maximal oxygen uptake ( $\mathrm{VO}_{2}$ max), proposed by Almeida et al. ${ }^{13}$ for the Brazilian population, was used. All patients continued taking their usual medication prescribed by their physicians.

\section{Statistical analysis}

Normality was measured using the Kolmogorov-Smirnov test. Depending on the distribution of the variable, continuous data were described through the mean and standard deviation or median and interquartile range and compared by ANOVA (Tukey) or Kruskal-Wallis test, as appropriate. Categorical variables were presented as a percentage and were compared by Chi-square test or Fisher's exact test, as appropriate.

The $\mathrm{VO}_{2}$ peak (in $\mathrm{mL} \cdot \mathrm{kg}^{-1} \cdot \mathrm{min}^{-1}$ ) adjusted for age and body mass index was the outcome variable of primary interest in this study and, therefore, was used as a dependent variable for regression modeling analyses. To identify important predictors of $\mathrm{VO}_{2}$ peak, a sequence of regression modeling analyzes were performed. Patient data were analyzed separately to determine the variables that were predictive of the $\mathrm{VO}_{2}$ peak within each group. Significantly different variables between groups were first analyzed in a univariate linear regression model. Then, those significantly associated in the univariate analysis ( $p$-value $<0.05$ ) were included in a multiple linear regression model. All data were stored and analyzed in the Statistical Package for the Social Sciences (SPSS) software for windows v. 20.0. A significance level of $5 \%$ was adopted.

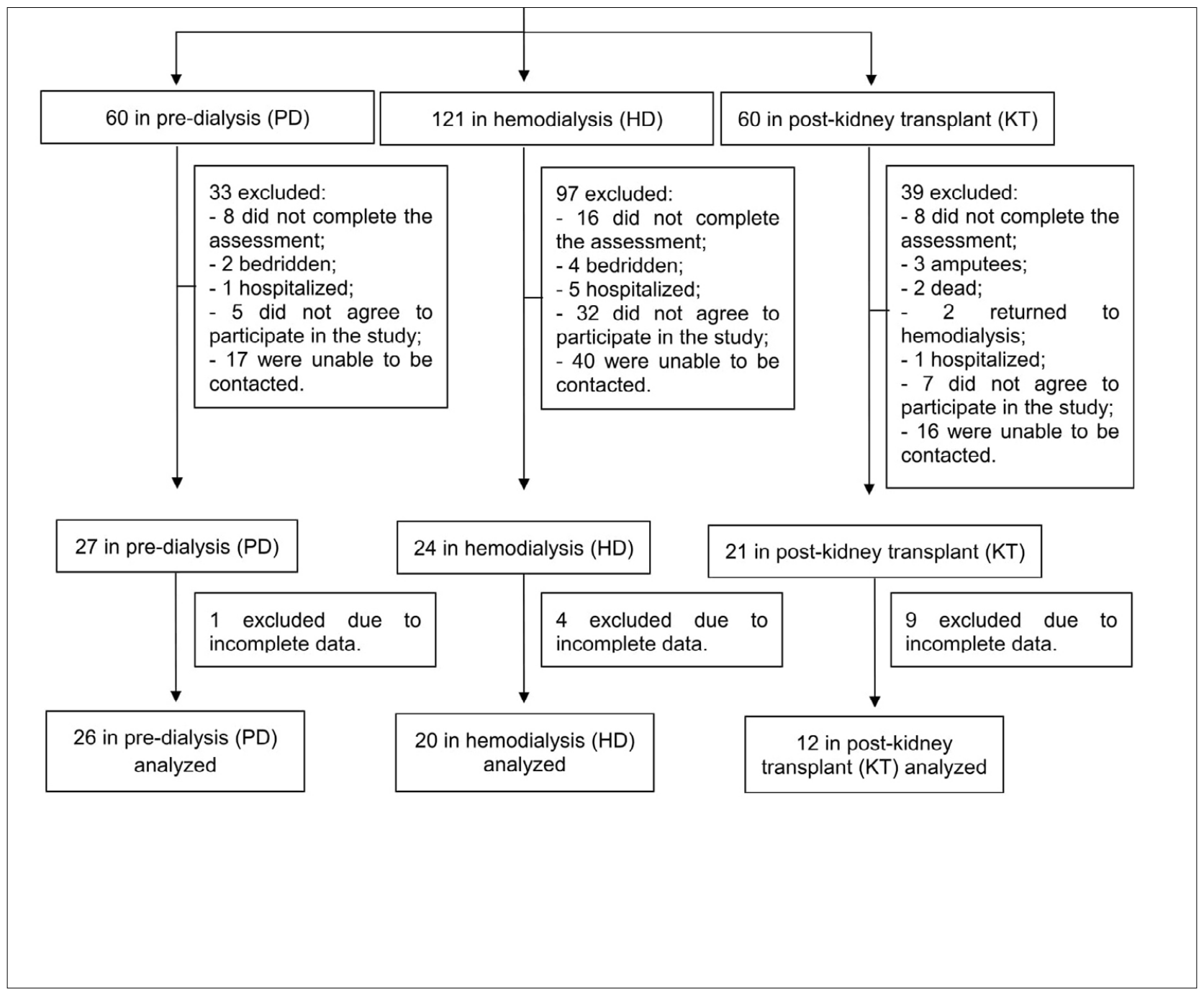




\section{RESULTS}

\section{Characteristics of the patient population}

Fifty-eight patients were included in this study. The characteristics of these patients are shown in Table 1. The CKD patients of the three groups had similar (a) sociodemographic and clinical characteristics: age ( $p$-value $=0.202)$, sex ( $p$-value $=0.526), B M I$ ( $p$-value $=0.790)$, time of CKD ( $p$-value $=0.084)$; and (b) prevalence of comorbidities such as: hypertension ( $p$-value $=0.340), D M(p$-value $=0.768)$, smoking ( $p$-value $=0.237$ ), and alcoholism ( $p$-value $=0.146$ ).

Biochemical data differed significantly between the PD, HD, and KT groups (Table 1). Creatinine and urea levels were higher in patients in the HD group when compared to patients in the PD group ( $p$-value $<0.001 ; p$-value $=0.005)$ and KT group (p-value $<0.001 ; p$-value $<0.001)$, respectively. Additionally, creatinine and urea levels were higher in patients in the PD group when compared to patients in the KT group ( $p$-value $=0.050$; $p$-value $=0.012$ ), respectively. Potassium was significantly higher in the PD group when compared to the HD $(p$-value $=0.050)$ and KT $(p$-value $=0.042)$ groups. Hemoglobin and hematocrit levels were lower, and consequently the percentage of patients with anemia was higher in the HD group when compared to the PD (p-value $=0.001 ; p$-value $=0.001)$ and KT groups (p-value<0.001; p-value<0.001).

\section{Functional cardiovascular reserve}

Metabolic data of the CPET for the three groups are presented in Fig. 2. When compared to patients in the KT group, patients in the HD group had lower $\mathrm{VO}_{2}$ peak ( $17.5 \pm 5.9$ vs. $23.2 \pm 8.2$ [p-value $=0.036$ ]), corresponding to $70.5 \%$ vs. $79.5 \%$ of the predicted $\mathrm{VO}_{2}$ peak, and $\mathrm{VO}_{2} \mathrm{AT}$ (14.0 \pm 5.2 vs. $18.3 \pm 4.7$ [p-value $=0.039$ ]), corresponding to $56.7 \%$ vs. $63.7 \%$ of the predicted $\mathrm{VO}_{2}$ peak. Patients in the PD group presented lower peak circulatory power values when compared to those in the HD group ( $p$-value=0.002). The OUES was significantly lower in the HD group when compared to the KT group (p-value=0.034).

\section{Independent predictors of $\mathrm{VO}_{2}$ peak}

The increase in age was negatively associated with $\mathrm{VO}_{2}$ peak in patients in the PD group $(b=-0.13$; $p$-value $=0.034)$, HD group ( $b=-0.33$; $p$-value $=0.002)$, and KT group ( $b=-0.66$, $p$-value $=0.011)$. A sedentary

TABLE 1. CHARACTERISTICS OF THE STUDY POPULATION IN THE DIFFERENT STAGES OF CHRONIC KIDNEY DISEASE

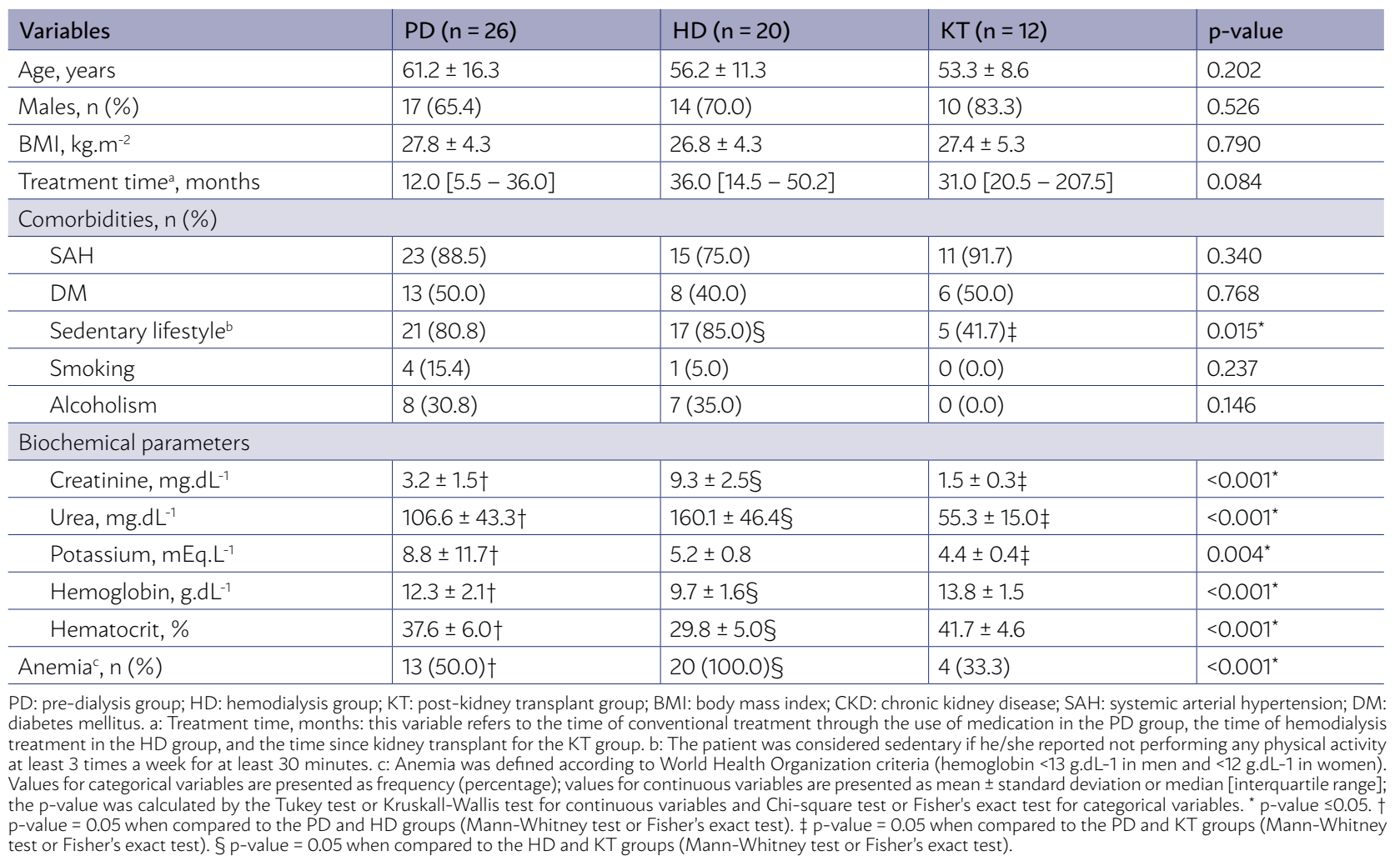



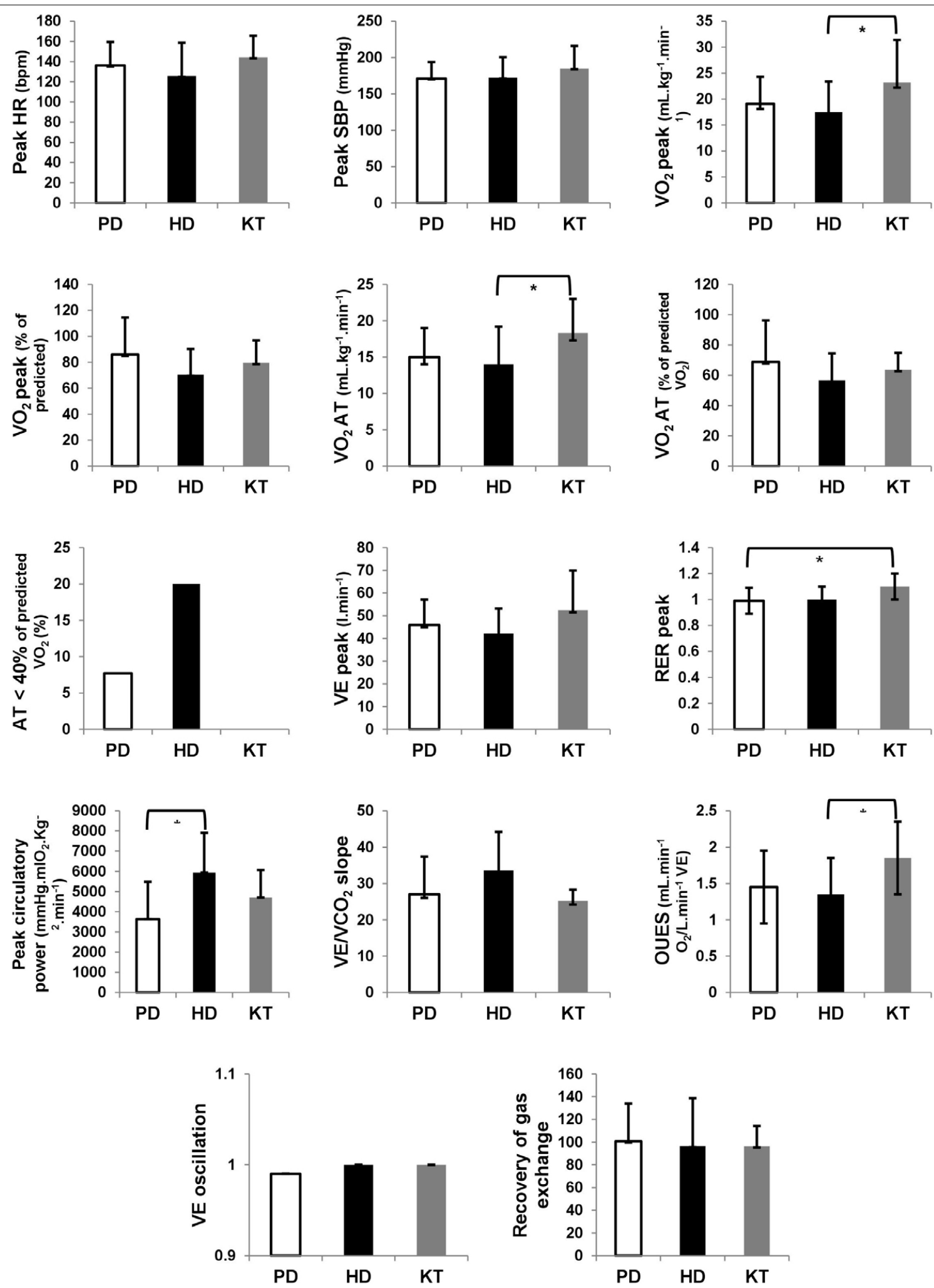

FIGURE 2

lifestyle was negatively and significantly associated with $\mathrm{VO}_{2}$ peak in patients in the KT group $(b=-$ 11.63, $\mathrm{p}$-value $=0.007)$, but not in the PD $(b=-1.85$, $p$-value $=0.487)$ and $\mathrm{HD}(b=-2.67$, $p$-value $=0.483)$ groups. The analysis of the multiple linear regression model for the KT group was performed. In the post-kidney transplant patient population, the constant $\mathrm{VO}_{2}$ peak was $54.59 \mathrm{~mL} \cdot \mathrm{kg}^{-1} \cdot \mathrm{min}^{-1}$ (adjusted $\mathrm{R}^{2}=0.76$; $\mathrm{p}$-value $<0.001)$. Higher age $(\mathrm{b}=-0.51$ [95\% $\mathrm{CI}=-0.85$ -0.18 ], $p$-value $=0.007)$ and sedentary lifestyle $(b=-9.28$ [95\% CI $=-14.83--3.72]$, $p$-value $=0.004)$ were significant predictors of lower $\mathrm{VO}_{2}$ peak. 


\section{DISCUSSION}

To our knowledge, this is the first study to evaluate measures of functional cardiovascular reserve in CKD patients and their association with the stages of kidney disease. Studies involving objective measures of the functional cardiovascular reserve are common for patients with heart disease $\mathrm{s}^{5,6}$, but for CKD patients, such studies are rare. In this study, we detected that $\mathrm{VO}_{2}$ peak and $\mathrm{VO}_{2} \mathrm{AT}$ in pre-dialysis, hemodialysis, and post-kidney transplant patients were reduced to $86 \%$ and $69 \%, 70 \%$ and $57 \%$, and $79 \%$ and $64 \%$ of the predicted value, respectively. A previous study has shown that reduced $\mathrm{VO}_{2}$ peak and $\mathrm{VO}_{2}$ AT values were associated with an increased risk of premature death in CKD patients ${ }^{\mathbf{1 4}}$. The present study further demonstrated that these parameters were significantly reduced in patients in the HD group compared to patients in the KT group. Other findings were that a) patients in the PD group had lower values of circulatory power when compared to those in the HD group, and b) OUES was significantly lower in the HD group when compared to the KT group.

OUES and circulatory power are variables which are evaluated less frequently than other traditional indices. Reduced OUES values ${ }^{5,15}$ and circulatory power $^{16,17}$ predict a worse prognosis in heart disease. Despite the great potential of these variables for clinical evaluation ${ }^{16-18}$, we did not find its use in the population of CKD patients, so our data are pioneering and can serve as a comparison for future studies. When comparing our OUES data with those from another population that also had a chronic limiting disease, such as patients with heart failure (1.96 ml.min $\left.{ }^{-1}\right)^{5}$, our patients performed worse regardless of the stage of CKD; only the KT group had slightly similar values.

$\mathrm{VO}_{2}$ peak, $\mathrm{VO}_{2} \mathrm{AT}$, and OUES were significantly better in post-kidney transplant patients, confirming their better exercise capacity when compared to patients in the HD group. These findings corroborate the literature that shows that kidney transplant is the only treatment that offers better survival compared to other renal replacement therapies. A successful kidney transplant reduces the risk of cardiovascular mortality when compared to maintaining dialysis therapy ${ }^{14,19,20}$. A recent study has demonstrated an improvement in the survival of patients with reduced functional cardiovascular reserve after kidney transplant ${ }^{14}$.

Although $\mathrm{VO}_{2}$ peak, $\mathrm{VO}_{2} \mathrm{AT}$, and OUES were better in the post-kidney transplant patients, all the other measures of the functional cardiovascular reserve were not significantly different from the patients in the PD and HD groups. This evidences that the improvement in exercise capacity is not complete, and that it depends on other factors such as the adoption of a healthy lifestyle with regular practice of exercise. For the KT patients, a sedentary lifestyle was a significant independent predictor of lower $\mathrm{VO}_{2}$ peak. Physical training has been shown to improve $\mathrm{VO}_{2}$ peak in patients undergoing long-term hemodialysis ${ }^{21}$.

Comparable reduced $\mathrm{VO}_{2}$ peak values $\left(18.8 \mathrm{~mL} \cdot \mathrm{kg}^{-1}\right.$. $\left.\mathrm{min}^{-1}\right)^{10} ;\left(18.5 \mathrm{~mL} \cdot \mathrm{kg}^{-1} \cdot \mathrm{min}^{-1}\right)^{21} ;\left(18.6 \mathrm{~mL} \cdot \mathrm{kg}^{-1} \cdot \mathrm{min}^{-1}\right)^{7}$ were documented in previous studies in CKD patients undergoing hemodialysis, but other measures of the cardiovascular reserve were not available for comparison $^{7,22}$. A comparison with data from Sietsema et al. ${ }^{7,22}$ reveals that our patients' hemoglobin levels were lower (11.2 and 11.8 g.dL ${ }^{-1}$ ), although the dialysis time was similar (41.5 and 32.0 months). Our patients were older and had a higher BMI, which may result in a lower $\mathrm{VO}_{2}$ peak; however, the $\mathrm{VO}_{2}$ peak was comparable across studies.

The hemoglobin levels of patients in our study were lower $\left(11.8 \mathrm{~g} . \mathrm{dL}^{-1}\right)$ when compared to the study of Ting et al. ${ }^{10}$, despite dialysis time (32.0 months), age (53.3 years), and BMI (27.2 kg.m ${ }^{-2}$ ) being similar. This study evaluated other objective measures of cardiovascular reserve such as $\mathrm{VO}_{2}$ peak (73.4\% of predicted), $\mathrm{VO}_{2}$ AT (11.2 mL. kg $\left.{ }^{-1} \cdot \mathrm{min}^{-1}\right), \mathrm{VO}_{2}$ AT (43.9\% of predicted $\mathrm{VO}_{2}$ ), VE/ $/ \mathrm{VCO}_{2}$ slope (29.3), and HR peak (132.8 bpm), which were also relatively similar to those found in our study; however, our HD patients presented worse performance, except in $\mathrm{VO}_{2} \mathrm{AT}$.

Patients in the studied HD group presented a higher prevalence of anemia and significantly lower hemoglobin and hematocrit levels when compared to patients in the PD and KT groups. It is known that the presence of anemia in CKD is determined by different factors such as relative erythropoietin (EPO) deficiency, iron deficiency, inflammation, hyperparathyroidism, blood loss, decreased half-life of red blood cells, and deficiency of folic acid and vitamin B12 $2^{23}$.

Creatinine and urea are markers traditionally used to characterize the impairment of glomerular function. In our study, the values of these two markers for all three groups support the values of erythrocyte parameters since the greater the renal damage, the lower the EPO production, and consequently, the lower the erythrocyte production leading to an anemic state ${ }^{24}$. Thus, even using recombinant 
human erythropoietin, hemodialysis patients present a greater degree of anemia, and a greater degree of functional impairment. Pre-dialytic patients still have higher hemoglobin concentrations due to better renal integrity. Patients after renal transplantation, due to the production of the grafted organ, are able to produce a greater amount of EPO and, therefore, have higher hemoglobin levels.

Hemoglobin and iron are involved in the processes of releasing oxygen to tissues, so they may affect exercise capacity. A recent study in patients with heart failure observed a significant reduction in exercise capacity in parallel to reduced hemoglobin levels, and in patients with anemia and iron deficiency, exercise capacity was significantly lower than in patients with isolated anemia or iron deficiency ${ }^{25}$. We observed a significant difference in hemoglobin levels between the PD, HD, and KT groups, and in the $\mathrm{VO}_{2}$ peak and $\mathrm{VO}_{2}$ AT between the HD and KT groups. However, in a subgroup analysis, we did not observe a significant difference in $\mathrm{VO}_{2}$ peak between patients with and without anemia (p-value=0.390); additionally, there was no correlation between hemoglobin levels and $\mathrm{VO}_{2}$ peak $(\mathrm{r}=0.189$; $\mathrm{p}$-value $=0.250)$ and $\mathrm{VO}_{2} \mathrm{AT}(\mathrm{r}=0.174$, $p$-value $=0.290)$. This evidences that in this population, regardless of the CKD stage, anemia did not significantly affect the measures of cardiovascular reserve and was not a predictor of $\mathrm{VO}_{2}$ peak.

This study is characterized by the initial exploration of measures of functional cardiovascular reserve in CKD patients and by comparing these measures between the different stages of the disease. Like any study, it has some limitations. First, although the literature indicates that measures of the functional cardiovascular reserve are prognostic markers in patients with heart failure, the cross-sectional nature and relatively small sample size of the present study did not allow us to expand the prognostic utility of both indices. Therefore, further prospective evaluations in this population are required to use these measures as prognostic markers.

\section{CONCLUSIONS}

Our study shows that patients with CKD present a reduction of functional cardiovascular reserve regardless of the stage of the disease they are in. However, hemodialysis patients presented a greater reduction of cardiovascular reserve when compared to post-kidney transplant patients. Since a sedentary lifestyle was an independent predictor of the lowest $\mathrm{VO}_{2}$ peak in post-kidney transplant patients, the importance of physical training to improve functional cardiovascular reserve is emphasized, especially in these patients.

\section{Authors' contributions}

Schneider J designed the study, analyzed the data, and wrote the manuscript. Fontela PC reviewed the analysis of the data and the manuscript and provided intellectual content of critical importance to the work described. Frizzo MN, Franz LBB, and Oliveira OB reviewed the manuscript. Winkelmann ER designed the study, reviewed the analysis of the data, and wrote the manuscript. All authors approved the final version of the manuscript.

\section{RESUMO}

OBJETIVO: Pacientes com doença renal crônica (DRC) apresentam redução no consumo de oxigênio no pico do exercício (VO 2 pico). Nenhum estudo avaliou medidas objetivas da reserva cardiovascular, além do $\mathrm{VO}_{2}$ pico e do $\mathrm{VO}_{2}$ no limiar anaeróbio (LA), e comparou essas medidas entre pacientes com DRC nos diferentes estágios da doença.

MÉTODOS: Cinquenta e oito pacientes [grupo pré-diálise $(P D)=26$, grupo hemodiálise (HD)=20 e grupo pós-transplante (PT)=12] foram incluídos. As seguintes medidas da reserva cardiovascular foram obtidas: 1) frequência cardíaca (FC) pico; 2) pressão arterial sistólica (PAS) pico; 3) VO $\mathrm{V}_{2}$ pico e \% do predito; 4) $\mathrm{VO}_{2} \mathrm{LA}$ e \% do VO predito; 5) potência circulatória pico; 6) eficiência ventilatória para a produção de dióxido de carbono (VE/VCO 2 slope); 7) eficiência ventilatória para o consumo de oxigênio (Oues); 8) recuperação das trocas gasosas.

RESULTADOS: $\mathrm{O} \mathrm{VO}{ }_{2}$ pico e o $\mathrm{VO}_{2}$ LA nos grupos PD, HD e PT foram reduzidos para $86 \%$ e $69 \%$, 70\% e $57 \%$, e $79 \%$ e $64 \%$ do valor previsto, respectivamente. Pacientes do grupo HD obtiveram VO ${ }_{2}$ pico $(17,5 \pm 5,9$ vs. $23,2 \pm 8,2[p=0,036])$ e VO 2 LA $(14,0 \pm 5,2$ vs. 18,3 $\pm 4,7$ $[p=0,039])$ mais baixo, comparado aos pacientes PT. A Oues foi significativamente menor no grupo HD comparado ao grupo PT $(p=0,034)$. Idade nos grupos PD, HD e PT, e sedentarismo no grupo PT foram preditores do $\mathrm{VO}_{2}$ pico.

CONCLUSÃO: Pacientes com DRC apresentam redução da reserva cardiovascular independentemente do estágio da doença. No entanto, pacientes em hemodiálise apresentam uma redução mais acentuada da reserva cardiovascular quando comparados aos pacientes pós-transplante.

PALAVRAS-CHAVE: Insuficiência renal crônica. Teste de esforço. Transplante de rim. Diálise renal. 


\section{REFERENCES}

1. American Thoracic Society; American College of Chest Physicians. ATS/ ACCP Statement on cardiopulmonary exercise testing. Am J Respir Crit Care Med. 2003;167(2):211-77.

2. Foley RN, Parfrey PS, Sarnak MJ. Epidemiology of cardiovascular disease in chronic renal disease. J Am Soc Nephrol. 1998;9(12 Suppl):S16-23.

3. Beddhu S, Baird BC, Zitterkoph J, Neilson J, Greene T. Physical activity and mortality in chronic kidney disease (NHANES III). Clin J Am Soc Nephrol. 2009;4(12):1901-6.

4. Arena R, Sietsema KE. Cardiopulmonary exercise testing in the clinical evaluation of patients with heart and lung disease. Circulation. 2011;123(6):668-80.

5. Arena R, Myers J, Hsu L, Peberdy MA, Pinkstaff S, Bensimhon D, et al. The minute ventilation/carbon dioxide production slope is prognostically superior to the oxygen uptake efficiency slope. J Card Fail. 2007;13(6):462-9.

6. Arena R, Myers J, Guazzi M. The clinical and research applications of aerobic capacity and ventilatory efficiency in heart failure: an evidence-based review. Heart Fail Rev. 2008;13(2):245-69.

7. Sietsema KE, Amato A, Adler SG, Brass EP. Exercise capacity as a predictor of survival among ambulatory patients with end-stage renal disease. Kidney Int. 2004;65(2):719-24.

8. Johansen KL. Physical functioning and exercise capacity in patients on dialysis. Adv Renal Replace Ther. 1999;6(2):141-8.

9. Sezer S, Elsurer R, Ulubay G, Ozdemir FN, Haberal M. Factors associated with peak oxygen uptake in hemodialysis patients awaiting renal transplantation. Transplant Proc. 2007;39(4):879-82.

10. Ting SMS, Hamborg T, McGregor G, Oxborough D, Lim K, Koganti S, et al. Reduced cardiovascular reserve in chronic kidney failure: a matched cohort study. Am J Kidney Dis. 2015;66(2):274-84.

11. Dall'Ago P, Chiappa GR, Guths H, Stein R, Ribeiro JP. Inspiratory muscle training in patients with heart failure and inspiratory muscle weakness. A randomized trial. J Am Coll Cardiol. 2006;47(4):757-63.

12. Gademan MG, Swenne CA, Verwey HF, van de Vooren $H$, Haest JC, van Exel $\mathrm{H}$ ), et al. Exercise training increases oxygen uptake efficiency slope in chronic heart failure. Eur | Cardiovasc Prev Rehabil. 2008;15(2):140-4.

13. Almeida AEM, Stefani CM, Nascimento JA, Almeida NM, Santos AC, Ribeiro $P$, et al. Equação de predição do consumo de oxigênio em uma população brasileira. Arq Bras Cardiol. 2014;103(4):299-307.
14. Ting $S M$, lqbal $H$, Kanji $H$, Hamborg T, Aldridge $N$, Krishnan N, et al. Functional cardiovascular reserve predicts survival pre-kidney and post-kidney transplantation. J Am Soc Nephrol. 2014;25(1):187-95.

15. Davies LC, Wensel R, Georgiadou P, Cicoira M, Coats AJ, Piepoli MF, et al. Enhanced prognostic value from cardiopulmonary exercise testing in chronic heart failure by non-linear analysis: oxygen uptake efficiency slope. Eur Heart J. 2006;27(6):684-90.

16. Jaussaud I, Blanc P, Derval N, Bordachar P, Courregelongue M, Roudaut R, et al. Ventilatory response and peak circulatory power: new functional markers of response after cardiac resynchronization therapy. Arch Cardiovasc Dis. 2010;103(3):184-91.

17. Madan N, Beachler L, Konstantinopoulos P, Worley S, Sun Z, Latson LA. Peak circulatory power as an indicator of clinical status in children after Fontan procedure. Pediatr Cardiol. 2010;31(8):1203-8.

18. Giardini A, Specchia S, Berton E, Sangiorgi D, Coutsoumbas G, Gargiulo G, et al. Strong and independent prognostic value of peak circulatory power in adults with congenital heart disease. Am Heart J. 2007;154(3):441-7.

19. Meier-Kriesche HU, Schold JD, Srinivas TR, Reed A, Kaplan B. Kidney transplantation halts cardiovascular disease progression in patients with end-stage renal disease. Am J Transplant. 2004;4(10):1662-8.

20. Sadaghdar H, Chelluri L, Bowles SA, Shapiro R. Outcome of renal transplant recipients in the ICU. Chest. 1995;107(5):1402-5.

21. Kouidi E), Grekas DM, Deligiannis AP. Effects of exercise training on noninvasive cardiac measures in patients undergoing long-term hemodialysis: a randomized controlled trial. Am J Kidney Dis. 2009;54(3):511-21.

22. Sietsema KE, Hiatt WR, Esler A, Adler S, Amato A, Brass EP. Clinical and demographic predictors of exercise capacity in end-stage renal disease. Am Kidney Dis. 2002;39(1):76-85.

23. Abensur $\mathrm{H}$. Iron deficiency in chronic kidney disease. Rev Bras Hematol Hemoter. 2010;32(Supl.2):84-8.

24. Tirmenstajn-Jankovic B, Dimkovic N, Perunicic-Pekovic G, Radojicic Z, Bastac D, Zikic S, et al. Anemia is independently associated with NT-proBNP levels in asymptomatic predialysis patients with chronic kidney disease. Hippokratia. 2013;17(4):307-12.

25. Ebner N, Jankowska EA, Ponikowski P, Lainscak M, Elsner S, Sliziuk V, et al. The impact of iron deficiency and anaemia on exercise capacity and outcomes in patients with chronic heart failure. Results from the studies investigating co-morbidities aggravating heart failure. Int | Cardiol. 2016;205:6-12. 